\title{
In vitro $\mathrm{RNA}$ interference against $\beta$-catenin inhibits the proliferation of pediatric hepatic tumors
}

\author{
SURASAK SANGKHATHAT ${ }^{1}$, TAKESHI KUSAFUKA ${ }^{1}$, JIANGYONG MIAO ${ }^{1}$, AKIHIRO YONEDA ${ }^{1}$, \\ KEIGO NARA $^{1}$, SEIJI YAMAMOTO ${ }^{2}$, YASAFUMI KANEDA ${ }^{2}$ and MASAHIRO FUKUZAWA ${ }^{1}$ \\ ${ }^{1}$ Department of Pediatric Surgery and ${ }^{2}$ Division of Gene Therapy Science, \\ Graduate School of Medicine, Osaka University, Osaka, Japan
}

Received October 10, 2005; Accepted November 25, 2005

\begin{abstract}
Mutations of $\beta$-catenin have been identified in the majority of pediatric hepatic malignancies, including hepatoblastoma (HB) and hepatocellular carcinoma (HCC), suggesting its important contribution in hepatic tumorigenesis in this age group. However, the role of B-catenin/canonical Wnt signaling pathway in the neoplastic growth of cancer cells has not been directly studied. To address B-catenin's capability in maintaining the malignant phenotype in established pediatric HB and HCC cell lines, HuH-6 and HepG2, harboring mutated and overexpressed $\beta$-catenin, we carried out a series of in vitro analyses through a transfection of short interfering RNAs (siRNAs) to generate a loss-of-function model. HuH-7, another HB cell line derived from a pediatric patient without a stabilizing mutation was used for comparison. RNA interference successfully manipulated the degradation of overexpressed $\beta$-catenin. In all cell lines, $\beta$-catenin mRNA was suppressed by $80-90 \%$ after $48 \mathrm{~h}$ of transfection, and a reduction of its protein expression was demonstrated. In HuH-6 and HepG2, the pre-existing $\beta$-catenin nuclear accumulation disappeared and reductions of $\beta$-catenin downstream target genes, $c$-myc and $c y c l i n D 1$, were also evidenced after the treatment. The in vitro proliferation of both cell lines was transiently inhibited. In contrast, the suppression of B-catenin in $\mathrm{HuH}-7$ did not lead to a significant change in the expression of target genes or cellular proliferation. Our data indicate that $\beta$-catenin can be considered a specific target for gene therapy in pediatric hepatic tumors with mutations and overexpression of this gene.
\end{abstract}

\section{Introduction}

Hepatoblastoma (HB) and hepatocellular carcinoma (HCC) comprise the majority of primary hepatic malignancy in the pediatric age group (1-3). The molecular pathogenesis of $\mathrm{HB}$

Correspondence to: Dr Takeshi Kusafuka, Department of Pediatric Surgery, Osaka University Graduate Medical School, 2-2 Yamadaoka, Suita, Osaka 565-0028, Japan

E-mail: kusafuka@pedsurg.med.osaka-u.ac.jp

Key words: ß-catenin, RNA interference, gene therapy and HCC remains largely unknown; however, both tumors shared common evidence suggesting that the canonical Wnt/ß-catenin signaling pathway may play roles in their tumorigenesis (4-6). Somatic mutations of $\beta$-catenin were detected in $75-80 \%$ of $\mathrm{HB}$ and up to $40 \%$ of $\mathrm{HCC}(7,8)$. Moreover, immunohistochemical studies revealed accumulation of $B$-catenin protein in almost all cases of $\operatorname{HB}(9,10)$ and more than $50 \%$ of HCC $(11,12)$. In experimental studies, enhanced proliferation and suppressed apoptosis have been demonstrated in murine hepatocytes stably transfected with mutated $\beta$-catenin (13). A study using transgenic mice expressing an oncogenic form of $\beta$-catenin demonstrated that its constitutive activation resulted in sustained hepatocellular proliferation that was not offset by apoptosis (14).

$\beta$-catenin mediated a transcription of downstream target oncogenes in the canonical Wnt signaling pathway through a T-cell transcription factors and lymphoid enhancer factor (Tcf/ Lef)-dependent mechanism $(4,6)$. In normally differentiated cells, an amount of cytoplasmic B-catenin is tightly regulated through its phosphorylation by an intracellular multiprotein complex composed of a key molecule, Glycogen synthetase kinase (GSK)- $\beta$, that functions together with Adenomatous polyposis coli $(A P C)$, Axin1 and Axin2. Effective phosphorylation leads $\beta$-catenin protein to subsequent degradation by an ubiquitin-proteosome pathway. A mutation, of $\beta$-catenin itself or any members in this complex, results in defective phosphorylation and, hence, stabilization and accumulation of intracellular B-catenin protein (6).

The majority of $\beta$-catenin mutations in $\mathrm{HB}$ occurred as deletions whereas the predominant mutations in HCC were missense mutations surrounding the $\mathrm{NH}_{2}$-terminal in exon 3 $(4,7-9,15,16)$. Such alterations affect the phosphorylation sites (codons 33, 37, 41 and 45) or flanking residues of codons 33 and 37 . Accumulated free $\beta$-catenin subsequently interacts with the transcription factor, Tcf/Lef, and enters the nucleus where Tcf/Lef functions as a nuclear binding domain for $\beta$ catenin to transactivate the downstream target oncogenes, including $c$-myc and cyclinD1 (17-19). Missense mutations of $A P C$ or $A X I N 1$ were also detected in human $\mathrm{HB}$ and $\mathrm{HCC}$, despite less frequency $(8,20)$.

Apart from its functions on cellular proliferation and differentiation in the Wnt signaling pathway, $\beta$-catenin also supports epithelial architecture by forming cell surface complexes with E-cadherin $(21,22)$. In HB or HCC harboring 
mutations of $\beta$-catenin or its related gene, nuclear localization of $\beta$-catenin can be detected whereas, in those without such stabilizing mutations, immunoreactivity is confined to their cell membranes (8). Such immunohistochemical clues suggested that particular functions of $\beta$-catenin in hepatic cancer with and without mutations may differ.

To address the role of $\beta$-catenin in maintaining a malignant phenotype of pediatric hepatic tumor with regard to its mutation status, we created a loss-of-function phenotype by in vitro knock-down of the gene at its mRNA level in a pediatric HCC cell line (HepG2) and an HB cell line (HuH-6), both harboring stabilizing mutations of $\beta$-catenin, in comparison with a pediatric HB cell line without $\beta$-catenin mutation (HuH-7).

In this study, we transfected artificially synthesized siRNAs designed to target the $\beta$-catenin gene using Haemagglutinating Virus of Japan envelope (HVJ-E) as a nucleotide delivery system (23). We found a dramatic clearance of nuclear and cytoplasmic immunoreactivity of $\beta$-catenin in cells with stabilizing mutations (HuH-6, HepG2), in concomitance with the reduction of $\beta$-catenin mRNA and $\beta$-catenin protein. The suppression of $\beta$-catenin downstream target genes, $c$-myc and cyclinD1, and inhibition of cellular proliferation were observed in both mutant cell lines. On the other hand, HB cells without such stabilizing mutation (HuH-7) displayed lower baseline expression of $\beta$-catenin and absent nuclear immunoreactivity. In $\mathrm{HuH}-7$, although $\beta$-catenin mRNA and protein could be suppressed by the treatment as well, no significant change in the expression of the target genes was detected and the influence of treatment on tumor cell proliferation was also less pronounced. These data confirmed the crucial role of stabilized B-catenin in the maintenance of tumor growth and also provided an in vitro gene therapeutic model for pediatric hepatic cancers, especially those with stabilizing mutations of $\beta$-catenin .

\section{Materials and methods}

Cell lines and culture conditions. Human hepatoblastoma cell line HuH-6 was obtained from the Japanese Collection of Research Bioresources (JCRB, Tokyo, Japan). Hepatocellular carcinoma cell line HepG2 and another hepatoblastoma cell line, HuH-7, were obtained from Riken Cell Bank (Tokyo, Japan). HepG2 cells were propagated and maintained in Minimum Essential Medium (Invitrogen, Inc.) supplemented with $10 \%$ fetal bovine serum (FBS) (Invitrogen, Inc.), 50 units/ $\mathrm{ml}$ penicillin, $50 \mu \mathrm{g} / \mathrm{ml}$ streptomycin and $0.1 \mathrm{mM}$ MEM nonessential amino-acids solution (Invitrogen, Inc.) The HuH-6 and HuH-7 cell lines were maintained in Dulbecco's modified Eagle's medium (DMEM) (Nacalai Tesque, Kyoto, Japan) supplemented with $10 \%$ FBS and the same antibiotics. All cell lines were incubated in a $37^{\circ} \mathrm{C}$ humidified atmosphere containing $5 \% \mathrm{CO}_{2}$. Mutations of $\beta$-catenin in HepG2 and HuH-6 have been reported in a previous work by De la Coste et al (24) and also were confirmed in this study.

DNA and cDNA preparation. Genomic DNA was extracted from each cell line using the High Pure PCR template preparation kit (Roche, Inc.), following the supplier's instructions. Total cellular RNA was prepared by RNAqueous RNA isolation kit (Ambion, Texas, USA), according to the manufacturer's protocol. First-strand cDNA was synthesized from $1 \mu \mathrm{g}$ of total RNA using MMLV reverse transcriptase (Clontech Laboratories, USA) and oligo(dT) primers.

$\beta$-catenin mutation characterization. Confirmation of $\beta$-catenin mutation in cell lines used polymerase chain reaction (PCR) and PCR-based direct sequencing. Briefly, genomic DNA was amplified by using two primer sets (BCAT1/2, BCAT3/4), which were designed by Koch et al (9). These two primer sets were utilized to detect point mutations and larger interstitial deletions involving exon 3 of the $\beta$-catenin gene, respectively. PCR and electrophoreses conditions were described in our previous publication (16). For sequencing, PCR products were purified using the QIAquick PCR purification kit (Qiagen, Inc.), and their nucleotide sequences were determined on both strands using a Dye Terminator cycle sequencing kit (Applied Biosystems, Inc.) on an automated sequencer (ABI PRISM ${ }^{\mathrm{TM}}$ 310 Genetic Analyser, Perkin-Elmer).

siRNA oligonucleotides. SMARTpool siRNA oligonucleotides with two thymidine residues (dTdT) at the 3'-end of the sequence were purchased from Dharmacon (Lafayatte, CO, USA). The siRNA oligonucleotides corresponded to nucleotides $445-463,570-588,607-625$ and $1732-1750$ of the human $\beta$-catenin gene (GeneBank access no. X87838). The sequences were as follows: siß-catenin-1 (sense, 5'-ACAAG TAGCTGATATTGAT-3'), siß-catenin-2 (sense, 5'-CCACT AATGTCCAGCGTTT-3'), siß-catenin-3 (sense, 5'-GCTGA AACATGCAGTTGTA-3'), siß-catenin-4 (sense, 5'-GATAA AGGCTACTGTTGGA-3').

Transfection. Transient transfection of siRNA was carried out using a Genome-One HVJ-E vector, (ISK Corp., Osaka, Japan), following the instruction manual. All transfection was performed with a final concentration of $100 \mathrm{nM}$ of siRNA in serum-free culture media. Briefly, siRNA and the viral envelope were mixed to form a transfection complex by centrifugation under a cool temperature. The cell was exposed to the vector-siRNA complex for a 1 -h period in order to avoid cytotoxic side-effects. Transfection efficiency was measured as approximately $60 \%$ in HuH-6 and HepG2 cell lines and $40 \%$ in $\mathrm{HuH}-7$ cell when evaluated by a fluorescein isothiocyanate (FITC)-labeled oligodeoxynucleotide under this transfection condition (data not shown).

Gene expression assays by real-time reverse transcriptionpolymerase chain reaction (RT-PCR). Twenty-four hours prior to transfection, $1.5 \times 10^{5}$ cells of HuH- 6 and HuH-7 or $9 \times 10^{5}$ cells of HepG2 were seeded in each well of a 6-well plate. After $48 \mathrm{~h}$, the cells were harvested for RNA extraction and cDNA synthesis. To quantitate the level of mRNA of $\beta$-catenin and its target genes, real-time RT-PCR was performed on an ABI PRISM 7700 sequence detection system with Sequence Detector V1.7 software (PE Applied Biosystems, Inc.), as described elsewhere (25). The primers and TaqMan probes used in this study are presented in Table I. Human GAPDH was used as an internal control. The copy numbers of $\beta$-catenin, $c$-myc and cyclinDl mRNA were standardized by the copy number of $G A P D H$ in each sample and expressed per 1,000 
Table I. Primers used in real-time quantitative PCR.

\begin{tabular}{ll}
\hline Gene & \multicolumn{1}{c}{ Sequences $\left(5^{\prime} \rightarrow 3^{\prime}\right)$} \\
\hline $\begin{array}{l}\text { B-catenin } \\
\text { Forward }\end{array}$ & CCTCTGATAAAGGCTACTGTTGGAT \\
Reverse & CTGATGTGCACGAACAAGCA \\
TaqMan probe & FAM-CCTTTGTCCCGCAAATCATGCA \\
& CCTT-TAMRA \\
GAPDH & \\
Forward & GAAGGTGAAGGTCGGAGTCA \\
Reverse & GAAGATGGTGATGGGATTTC \\
TaqMan probe & FAM-CAAGCTTCCCGTTCTCAGCC- \\
& TAMRA \\
c-Myc & \\
Forward & TCAAGAGGTGCCACGTCTCC \\
Reverse & TCAAGAGGTGCCACGTCTCC \\
TaqMan probe & FAM-CAGCACAACTACGCAGCGCCT \\
& CC-TAMRA \\
CyclinD1 & \\
Forward & TCTACACCGACGGCTCCATC \\
Reverse & CATCTGTGGCACAAGAGGCA \\
TaqMan probe & FAM-CGGAGCATTTCATACCAGAA \\
& GGGAAAGC-TAMRA \\
\hline
\end{tabular}

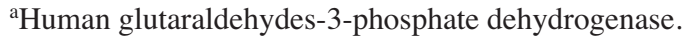

copies of GAPDH. Time-courses of mRNA expression were followed on post-transfection days 2, 3, 5 and 7 in HuH-6 cells.

$\beta$-catenin protein quantitation. Transfection was performed under the same condition as gene expression assay. Protein quantitation was performed using Western blotting, as described elsewhere (26). Briefly, cells were harvested $72 \mathrm{~h}$ post transfection and lysed using RIPA lysis buffer (Upstate, Inc.). After measuring by BCA protein assay (Pierce Biotechnology, Inc.), approximately $20 \mu \mathrm{g}$ of protein was loaded into each well on a $10 \%$ sodium dodecyl sulfate-polyacrylamide gel for electrophoresis, and subsequently transferred onto a polyvinyl difluoride membrane. The membrane was incubated with anti- $\beta$-catenin monoclonal antibody (Transduction Laboratories, KY, USA) at a dilution of $0.5 \mu \mathrm{g} / \mathrm{ml}$, for $24 \mathrm{~h}$ at $4^{\circ} \mathrm{C}$. It was then incubated with a horseradish peroxidaseconjugated anti-mouse antibody for $1 \mathrm{~h}$ and developed using an enhanced chemiluminescence system (Amersham Biosciences, Inc.).

Immunocytochemistry. Cells were plated on cover glasses placed in a 6-well plate in the same densities as for mRNA expression assay. On post-transfection day 3 , the cells were fixed in $4 \%$ paraformaldehyde for standard indirect immunofluorescence staining. Briefly, fixed cover glasses were rinsed in PBS, permeabilized with $1 \%$ Triton $\mathrm{X}-100$ for $1 \mathrm{~h}$ and then blocked with $10 \%$ normal rabbit serum for $30 \mathrm{~min}$ before incubation with anti- $\beta$-catenin antibody $(0.5 \mu \mathrm{g} / \mathrm{ml}$; Transduction Laboratories, KY, USA) overnight at $4^{\circ} \mathrm{C}$. For visualization, FITC-conjugated rabbit anti-mouse immunoglobulins (6 mg/ml; Dako, Denmark) were used as a secondary antibody. Cover glasses were incubated in PBS containing $0.02 \%$ propidium iodide for nuclear staining and then washed and mounted with fluorescence mounting medium (Dako Cytomation, Japan). Photographs were taken using a Keyence VB6000 digital photography system (Keyence, Japan) attached to a Nikon Eclipse C1000 microscope (Nikon, Japan). The negative control neglected the $\beta$-catenin antibody but followed the other same staining procedures.

Cell viability assay. Cell viability was determined using the WST-1 cell counting kit (Wako Pure Chemical Industries, Osaka, Japan). The principle of this method is a colorimetric detection of mitochondrial dehydrogenase in viable cells (27). Prior to transfection, HuH-6 and $\mathrm{HuH}-7$ cells were seeded at a density of $5 \times 10^{3}$ cells in $100 \mu 1$ of medium into each well of 96-well plates. HepG2 were seeded at $3 \times 10^{4}$ cells/well. On post-transfection day 2, $10 \mu \mathrm{l}$ of WST-1 solution was added to each well. After incubation at $37^{\circ} \mathrm{C}$ for $60 \mathrm{~min}$, the absorbency of the treated samples against a blank control was measured under an immuno-reader (Immuno Mini NJ-2300, Nippon Inter-Med K.K., Tokyo, Japan) with $450 \mathrm{~nm}$ as a detection wavelength and $650 \mathrm{~nm}$ as a reference wavelength.

Cell counting analysis. To estimate the time-course of cell proliferation, $3 \times 10^{5}$ cells of HepG 2 and $5 \times 10^{5}$ cells of HuH-6 or HuH-7 were plated in standard 12-well culture plates before transfection. After siRNA transfection, cells were harvested every $24 \mathrm{~h}$ for up to 6 days after transfection ( 5 days for HuH-7) and documented using an automatic cell counter instrument (Beckman Coulter Co., Japan). For comprehensive comparison, the results in each time-point were expressed as a percentage of the number of cells in the no treatment group.

Apoptosis evaluation. For HuH-6 and HuH-7, apoptotic assay was performed semi-quantitatively by using the ApopTag Plus Fluorescein In Situ apoptosis detection kit (Serologicals Corp., USA) and was based on the TUNEL principle. Cells were seeded on coverslips in a 6-well plate and transfected using the same protocol as for the expression study. After 3 days, the cells were harvested and subjected to detection, according to the manufacturer's instructions. Apoptotic cells were observed under a fluorescence microscope.

Statistical analysis. All experiments were performed at least three times under similar conditions and the typical results were demonstrated. Unless stated otherwise, data were presented as means together with standard deviation for each parameter. Statistical analysis was performed using an unpaired Student's t-test with significance considered as p-value $<0.01$.

\section{Results}

Identification of $\beta$-catenin mutation and overexpression in each hepatic tumor cell line. To confirm B-catenin mutations in each hepatoblastoma cell line, we performed PCR and direct 


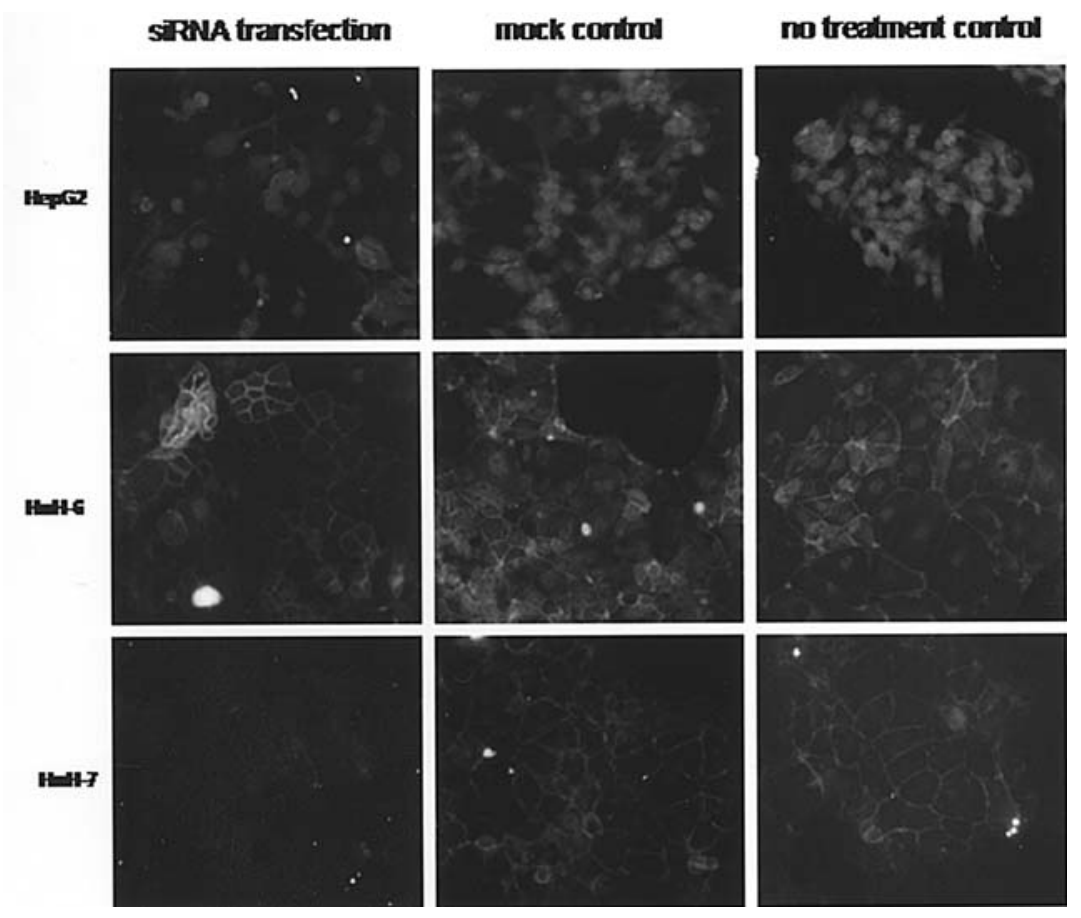

Figure 1. Immunocytochemical study demonstrated B-catenin nuclear staining pattern in HepG2 and HuH-6 cells and only membrane immunoreactivity in HuH-7. After siRNA treatment, HuH-6 and HepG2 revealed disappearance of nuclear localization. Disappearance of membrane staining also occurred in HepG2 while membrane reactivity remained weakly positive in $\mathrm{HuH}-6$. HuH-7 showed almost no positive immunoreactivity to $\beta$-catenin antibody after the treatment. No significant change was found in the mock transfection group. Photographs were taken at x20 magnification.
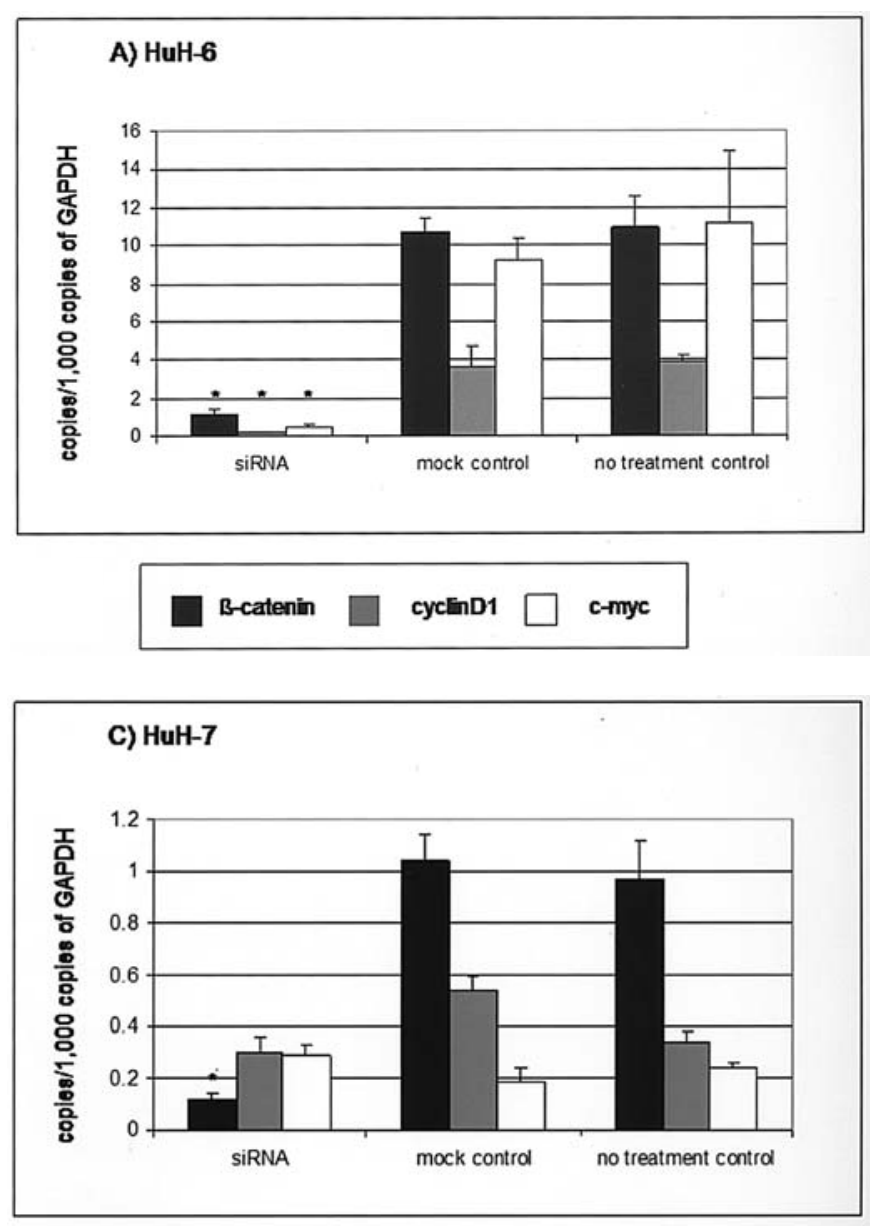

B-catenin

cyclinD1 c-myc

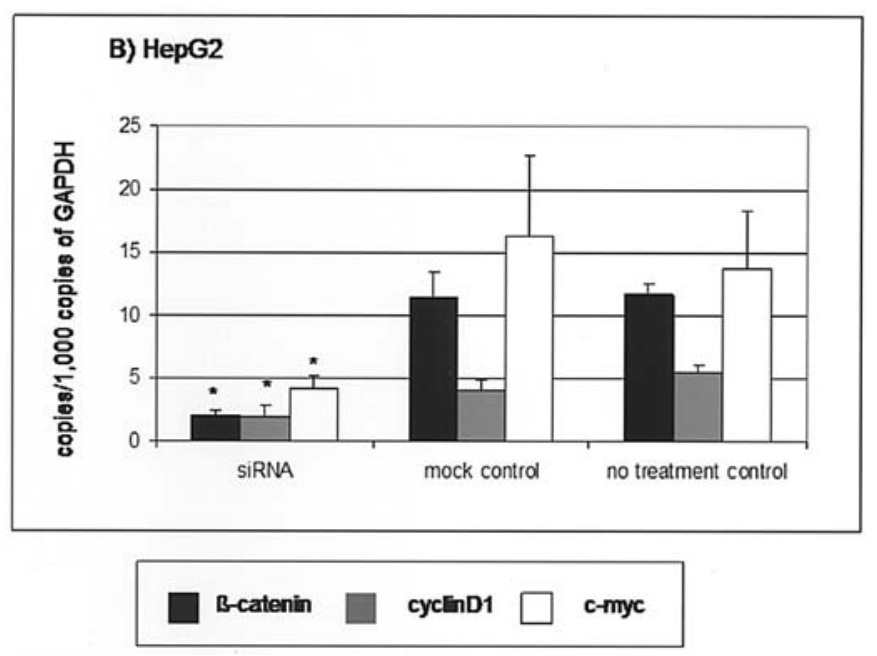

Figure 2. Assessment of mRNA expression of $ß$-catenin and its downstream targets, c-myc and cyclinD1, by real-time RT-PCR. The study showed significant reduction of $ß$-catenin expression in the siRNA treatment group of all cells studied. The magnitude of suppression was approximately 80$90 \%$ of baseline level. Significant reduction of downstream target gene expression was evidenced in HuH-6 (A) and HepG2 (B), but not in HuH-7 (C) $\left({ }^{*} \mathrm{p}<0.01\right)$.

sequencing analyses. In all cell lines, the PCR product for primers BCAT1/2 showed a normal size on agarose gel; however, interstitial deletion of the $\beta$-catenin gene in HepG2 cells was detected by PCR with primers spanning exon 3 


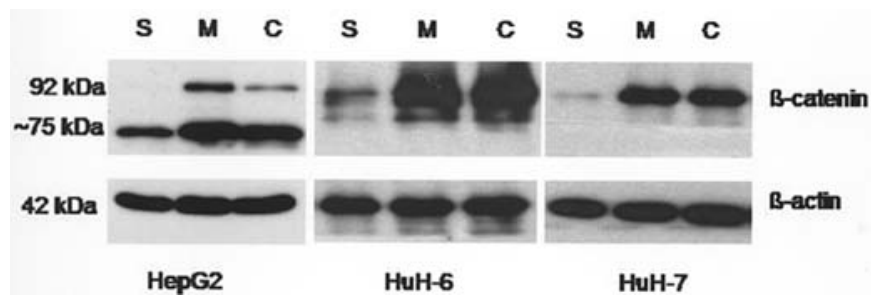

Figure 3. Western blotting of $B$-catenin from the whole cell lysates. The study revealed reduction of cellular B-catenin in all cells studied. In HepG2, reduction of the expression of both wild-type (upper band) and aberrant protein derived from the mutated sequence occurred (lower band, approximately $70 \mathrm{kDa})$. S, siRNA treatment; $\mathrm{M}$, mock control; $\mathrm{C}$, no treatment control.

(BCAT3/4). Subsequent direct sequencing revealed a 348nucleotide in-frame deletion at codon 25-140 of B-catenin (data not shown), resulting in a 116 amino-acid deletion. Direct sequencing of BCAT1/2 PCR products also revealed a missense mutation at codon 34 (Gly34Val) in HuH-6 and wild-type sequence in $\mathrm{HuH}-7$. Consistent with the mutation status, intense nuclear accumulation of $\beta$-catenin was found in HepG2 and HuH-6 cells whereas, in $\mathrm{HuH}-7$, only a membrane staining pattern appeared in moderate intensity, (Fig. 1, right column).

siRNA knock-down expression of $\beta$-catenin independent of the localization of the protein. At post-transfection day 2 , the level of $\beta$-catenin mRNA decreased significantly in all siRNA treatment groups (Fig. 2). Assay of the B-catenin protein by Western blotting also showed an obvious reduction of $\beta$-catenin protein in the treatment groups of all cell lines (Fig. 3). Although the suppression of $\beta$-catenin expression occurred in all cell lines studied, significant changes of target gene $c$-myc and cyclinDl expression were limited to cell lines with $\beta$-catenin mutations, HuH-6 and HepG2 (Fig. 2).

When the time-course of expression was followed in HuH-6, it appeared that $\beta$-catenin knock-down lasted for 3 days after the transfection (Fig. 4). The nadir level of reduction occurred around post-transfection days 2 and 3 when the Bcatenin mRNA level was suppressed to $40 \%$ of the control.

The expression of target oncogenes $c$-myc and cyclinDl decreased and recovered in the same pattern but to a lesser extent than that of $\beta$-catenin.

RNA interference abducted $\beta$-catenin from the nucleus. After siRNA treatment, immunocytochemistry demonstrated a dramatic clearance of nuclear accumulation. In HuH-6, intense nuclear staining of $\beta$-catenin completely disappeared, leaving only weak staining on cell membranes (Fig. 1). In HepG2 cells, although weak nuclear staining reactivity remained observable in some cells, the majority had a 'blank-cell appearance' after treatment.

In $\mathrm{HuH}-7$, of which pre-treatment staining showed a normal epithelial pattern of membrane localization, there was no positive immunoreactivity after the treatment.

RNA interference suppressed hepatic cancer cell proliferation. In WST-1 viability assay, the treatment groups in all cell lines showed significantly reduced viable cell numbers, compared

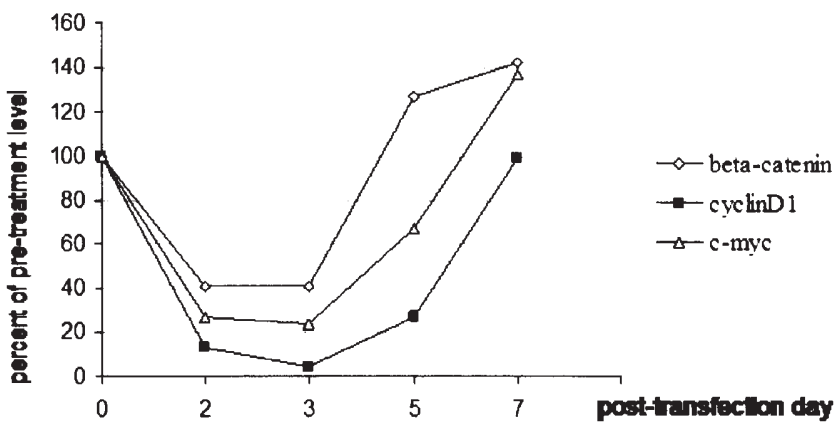

Figure 4. Time-course curve of relative expression of $\beta$-catenin and its targets, $c-m y c$ and $c y c l i n D 1$. Results were expressed in percentage of baseline value of each cell line before treatment. Note that the maximum suppression happened around post-transfection days 2 and 3 .

to the mock transfection and no treatment controls (Fig. 5A). However, the growth suppression level was less in HuH-7 than in the other two cell lines. The WST-1 results were consistent with the growth study by direct cell counting, in which the growth suppression appeared to last approximately 4 days in HepG2 and HuH-6 and not more than 2 days in HuH-7 (Fig. 5B).

Apoptosis did not increase after $\beta$-catenin knock-down. Using in situ TUNEL assay, there were more fluorescence positive cells in HuH-6 than in HuH-7. However, there was no significant difference between the siRNA treatment group, mock and no treatment control of each cell line.

\section{Discussion}

The canonical Wnt/ß-catenin signaling pathway is involved in the tumorigenesis of various cancers in humans $(4,6,28)$. In the pediatric age group, our previous study and that of others found $\beta$-catenin mutations in the majority of hepatoblastoma, solid and cystic tumors of the pancreas, and a number of nephroblastoma (8-10,15,16,28-30). A common feature occurring among these Wnt associated tumors is the nuclear localization of B-catenin protein, a molecule which plays its central role in modulating the transcription of target oncogenes in the pathway.

The nuclear accumulation of $\beta$-catenin is determined largely by an amount of free cytosolic $\beta$-catenin and the balance of nuclear influx and efflux (31). Mutations affecting $\beta$-catenin regulatory phosphorylation sites or their flanking residues prohibit an effective degradation of $\beta$-catenin protein by $G S K 3-\beta$, leading to its pathological stabilization. Free protein in the cytoplasm forms complexes with the transcription factor, Lef/Tcf, to enter the nucleus where it activates downstream target genes that control cellular growth $(10,36)$. According to this signaling scheme, the large deletion at exon 3 in HepG2 and the point mutation at codon 34 in HuH-6 explains the strong B-catenin nuclear staining patterns in both cell lines. On the other hand, HuH-7, a HB carrying wild-type $\beta$-catenin, showed only weak immunoreactivity along the cytoplasmic membranes. From this fundamental evidence, it can be hypothesized that knocking-down $\beta$-catenin in those tumor cell lines with mutated and/or overexpression will cause a negative impact on their growth. 
A

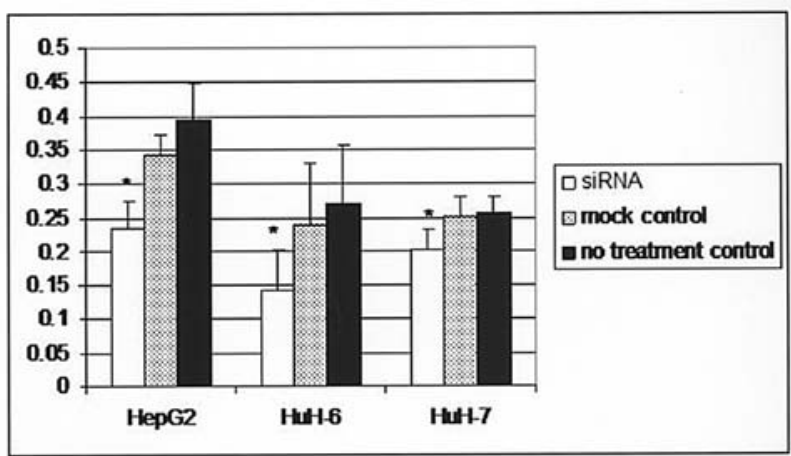

B

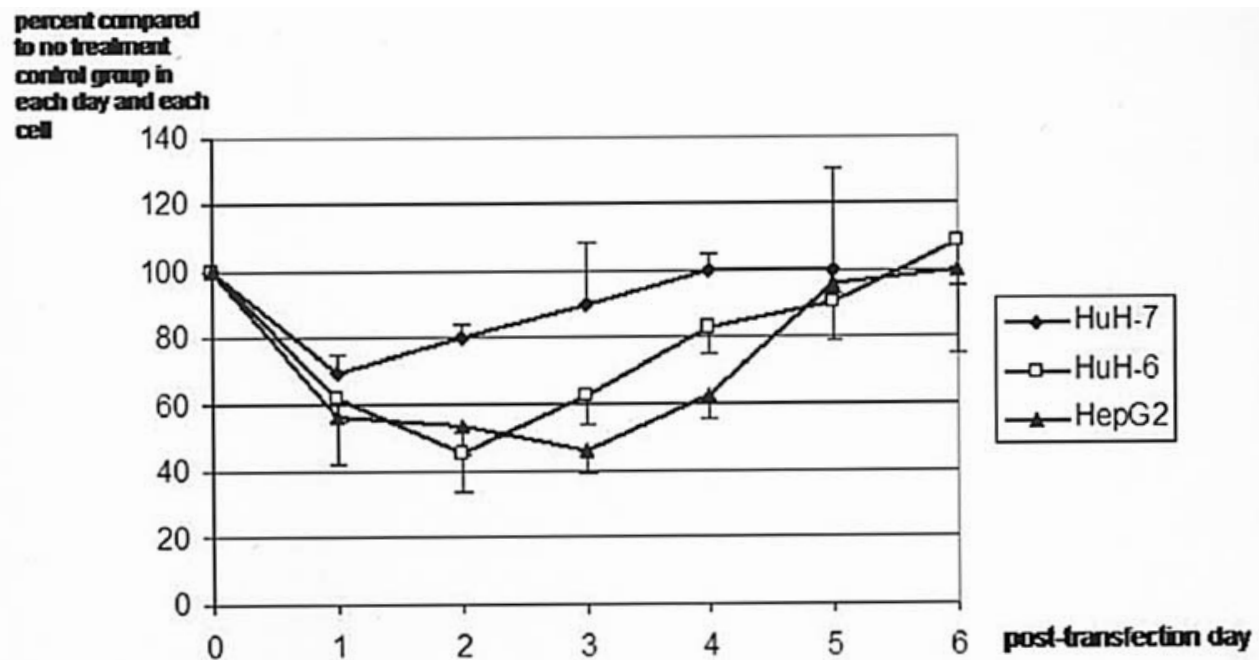

Figure 5. (A) WST-1 study on post-transfection day 2 demonstrated a significant reduction in cell viability in the siRNA-treated group of all three cell lines studied $\left({ }^{*} \mathrm{p}<0.01\right)$. (B) Time-course study of cell numbers by direct counting demonstrated that a reduction in total cell amount transiently occurred to varying degrees among the three cells. Growth suppression in HuH-7, although significant, was only marginal and occurred in a shorter period than in HuH-6 and HepG2.

siRNA are synthetic short dsRNA that, when introduced into a cell, induce the destruction of homologous singlestranded RNA (32-34). Recently developed RNA interference technology employs molecules to provide highly specific genetic silencing, which is an advantage to functional genetic study. Moreover, a therapeutic advantage can also be explored. A recent study by Verma and colleagues successfully used siRNA to knock-down $\beta$-catenin in an experimental model of colonic cancer (35). As a result, inhibition of colon cancer cell proliferation was demonstrated both in soft agar and nude mice. In our experiments, siRNA successfully reduced $\beta$-catenin in the mRNA level, leading to a subsequent reduction in its protein, as evidenced by the lower amount of total cellular B-catenin protein in Western blot analysis. It should be noticed that, in HepG2 cells, both wild-type and truncated protein were affected by the treatment.

In $\mathrm{HuH}-6$ and HepG $2, \beta$-catenin knock-down also resulted in a reduction of the expression of $c-m y c$ and $c y c l i n D 1$, two well-known downstream targets of $\beta$-catenin in the canonical Wnt/ß-catenin signaling pathway $(18,19)$. The evidence confirmed that $\beta$-catenin manipulation in these two cells provided sequential alterations to a more distal part of the signaling pathway. $c-M y c$ and $c y c l i n D 1$ promote cell-cycle progression through $\mathrm{G} 1$ to $\mathrm{S}$ phase transition acceleration (36). CyclinD1 expression has been correlated with $\beta$-catenin mutations in a series of clinical HB (15) and in experimental mice HCC (37). Our data provide supportive evidence that $c-m y c$ and $c y c l i n D 1$ are downstream responders of $\beta$-catenin in hepatic tumor cells with $\beta$-catenin mutations.

Our study also demonstrated that post-transcriptional knock-down resulted in the clearance of nuclear accumulated ß-catenin. Nuclear accumulation has been suspected to be the pathological signature which discriminates tumor cells harboring mutations from normally developed cells $(4,6,10,24)$. This exclusive feature allows $\beta$-catenin to be an interesting candidate for targeted therapy. Synchronous with the reduction of nuclear immunoreactivity, proliferation of $\mathrm{HuH}-6$ and HepG2 significantly reduced. The data support the role of $\beta$-catenin in the growth of these cell lines of pediatric $\mathrm{HB}$ and HCC. Marginal growth inhibition after $\beta$-catenin knock-down in $\mathrm{HuH}-7$, the wild-type counterpart, suggested that B-catenin contributes much less in the proliferation function of this cell line, as evidenced by its absence of nuclear immunoreactivity and relatively low baseline expression level of $\beta$-catenin and its downstream target genes.

Regarding the growth promoting function of $\beta$-catenin, previous study demonstrated enhanced proliferation of murine hepatocytes after a stable transfection of mutated $\beta$-catenin. Our study which was performed in the opposite direction gave a concordant summarization. However, according to our 
apoptosis assay, the growth inhibition was not likely to be a result of increased apoptosis.

In the transfection experiment, HVJ-E provided higher transfection efficiency than liposome-based transfection vectors. This viral envelope vector also has an advantage in its potential use in in vivo application (23). The effect of siRNA treatment on cellular proliferation was temporary, lasting not longer than one week. This incomplete response could be explained by the transience in intracellular stability of an externally induced siRNA, as it appeared that the RNA expression in HuH-6 reached maximum inhibition within the first few days of treatment and then quickly recovered to its pre-treatment level. Recent advances in RNA interference technology reported that de novo synthesis of double-stranded interfering RNA via an expression plasmid constructed to transcribe short hairpin RNA could achieve prolonged silencing (38).

In conclusion, we performed in vitro knocking-down of $\beta$-catenin, which has been suspected to be a key player in the tumorigenesis of pediatric $\mathrm{HB}$ and $\mathrm{HCC}$. We demonstrated that siRNA transfection dramatically silenced this gene in terms of reduction in mRNA expression, clearance of nuclear accumulation and decrease in total cellular B-catenin protein. The treatment ultimately resulted in the suppression of in vitro tumor cell progression in cell lines that harbor $\beta$-catenin mutations. The data lend a novel model of in vitro growth inhibition of pediatric hepatic epithelial cancers with $\beta$-catenin mutations through a precise genetic manipulation at the posttranscriptional level.

\section{Acknowledgements}

This study was partially supported by a Grant-in-Aid from the Ministry of Education, Science, Sports and Culture of Japan (Grant no. 6591785).

\section{References}

1. Shafer DF and Sorrel MF: Hepatocellular carcinoma. Lancet 353: 1253-1257, 1999.

2. Reynolds M: Pediatric liver tumors. Semin Pediatr Oncol 16: 159-172, 1999.

3. Schnater JM, Köhler SE, Lamers WH, Schweinitz D and Aronson D: Where do we stand with hepatoblastoma? A review. Cancer 98: 668-678, 2003.

4. Koesters R and von Knebel Doeberitz M: The Wnt signaling pathway in solid childhood tumors. Cancer Lett 198: 123-138, 2003.

5. Buendia MA: Genetics of hepatocellular carcinoma. Semin Cancer Biol 10: 185-200, 2000.

6. Polakis P: Wnt Signaling and cancer. Genes Dev 14: 1837-1851, 2000.

7. Buendia MA: Genetic alterations in hepatoblastoma and hepatocellular carcinoma: common and distinctive aspects. Med Pediatr Oncol 39: 530-535, 2002.

8. Taniguchi K, Roberts LR, Aderca IN, Dong X, Qian C, Murphy LM, Nagorney DM, Burgart LJ, Roche PC, Smith DI, Ross JA and Liu W: Mutational spectrum of beta-catenin, AXIN1 and AXIN2 in hepatocellular carcinomas and hepatoblastomas. Oncogene 21: 4863-4871, 2002.

9. Koch A, Denkhaus D, Albrecht S, Leuschner I, von Schweinitz D and Pietsch T: Childhood hepatoblastomas frequently carry a mutated degradation targeting box of the beta-catenin gene. Cancer Res 59: 269-273, 1999.

10. Jeng YM, Wu MZ, Mao TL, Chang MH and Hsu HC: Somatic mutations of beta-catenin play a crucial role in the tumorigenesis of sporadic hepatoblastoma. Cancer Lett 152: 45-51, 2000 .
11. Ihara A, Koizumi H, Hashizume R and Uchikoshi T: Expression of epithelial cadherin and alpha- and beta-catenins in nontumoral livers and hepatocellular carcinomas. Hepatology 23: 1441-1447, 1996.

12. Huang H, Fujii H, Sankila A, Mahler-Araujo BM, Matsuda M, Cathomas $\mathrm{G}$ and Ohgaki $\mathrm{H}$ : Beta-catenin mutations are frequent in human hepatocellular carcinomas associated with hepatitis $\mathrm{C}$ virus infection. Am J Pathol 155: 1795-1801, 1999

13. Shang XZ, Zhu H, Lin K, Tu Z, Chen J, Nelson DR and Liu C: Stabilized beta-catenin promotes hepatocyte proliferation and inhibits TNFalpha-induced apoptosis. Lab Invest 84: 332-341, 2004.

14. Cadoret A, Ovejero C, Saadi-Kheddouci S, Souil E, Fabre M, Romagnolo B, Kahn A and Perret C: Hepatomegaly in transgenic mice expressing an oncogenic form of beta-catenin. Cancer Res 61: 3245-3249, 2001.

15. Takayasu H, Horie H, Hiyama E, et al: Frequent deletions and mutations of the beta-catenin gene are associated with overexpression of cyclin D1 and fibronectin and poorly differentiated histology in childhood hepatoblastoma. Clin Cancer Res 7: 901-908, 2001.

16. Udatsu Y, Kusafuka T, Kuroda S, Miao J and Okada A: High frequency of beta-catenin mutations in hepatoblastoma. Pediatr Surg Int 17: 508-512, 2001

17. Hsu SC, Galceran J and Grosschedl R: Modulation of transcriptional regulation by LEF-1 in response to Wnt-1 signaling and association with beta-catenin. Mol Cell Biol 18: 4807-4818, 1998.

18. Tetsu $\mathrm{O}$ and McCormick F: Beta-catenin regulates expression of cyclin D1 in colon carcinoma cells. Nature 398: 422-426, 1999.

19. He TC, Sparks AB, Rago C, Hermeking H, Zawel L, Da Costa LT, Morin PJ, Vogelstein B and Kinzler KW: Identification of c-MYC as a target of the APC pathway. Science 281: 1509-1512, 1998.

20. Miao J, Kusafuka T, Udatsu Y and Okada A: Sequence variants of the Axin gene in hepatoblastoma. Hepatol Res 25: 174-179, 2003.

21. Gottardi CJ and Gumbiner BM: Adhesion signaling: how betacatenin interacts with its partners. Curr Biol 11: R792-R794, 2001.

22. Kamei J, Toyofuku T and Hori M: Negative regulation of $\mathrm{p} 21$ by beta-catenin/TCF signaling: a novel mechanism by which cell adhesion molecules regulate cell proliferation. Biochem Biophys Res Commun 312: 380-387, 2003.

23. Kaneda Y, Nakajima T, Nishikawa T, Yamamoto S, Ikegami H, Suzuki N, Nakamura H, Morishita $R$ and Kotani $H$ : Hemagglutinating virus of Japan (HVJ) envelope vector as a versatile gene delivery system. Mol Ther 6: 219-226, 2002.

24. De la Coste A, Romagnolo B, Billuart P, Renard CA, Buendia MA, Soubrane O, Fabre M, Chelly J, Beldjord C, Kahn A and Perret C: Somatic mutations of the beta-catenin gene are frequent in mouse and human hepatocellular carcinomas. Proc Natl Acad Sci USA 95: 8847-8851, 1998.

25. Tacke F, Trautwein C, Zhao S, Andreeff M, Manns MP, Ganser A and Schoffski P: Quantification of hepatic thrombopoietin mRNA transcripts in patients with chronic liver diseases shows maintained gene expression in different etiologies of liver cirrhosis. Liver 22: 205-212, 2002.

26. Ohno S, Nishi T, Kojima Y, Haraoka J, Ito H and Mizuguchi J: Combined stimulation with interferon alpha and retinoic acid synergistically inhibits proliferation of the glioblastoma cell line GB12. Neurol Res 24: 697-704, 2002.

27. Scudiero DA, Shoemaker RH, Paull KD, Monks A, Tierney S, Nofziger TH, Currens MJ, Seniff D and Boyd MR: Evaluation of a soluble tetrazolium/formazan assay for cell growth and drug sensitivity in culture using human and other tumor cell lines. Cancer Res 48: 4827-4833, 1988.

28. Giles RH, van Es JH and Clevers H: Caught up in a Wnt storm: Wnt signaling in cancer. Biochim Biophys Acta 1653: 1-24, 2003.

29. Kusafuka T, Miao J, Kuroda S, Udatsu Y and Yoneda A: Codon 45 of the beta-catenin gene, a specific mutational target site of Wilms' tumor. Int J Mol Med 10: 395-399, 2002.

30. Miao J, Kusafuka T, Kuroda S, Yoneda A, Zhou Z and Okada A: Mutation of beta-catenin and its protein accumulation in solid and cystic tumor of the pancreas associated with metastasis. Int J Mol Med 11: 461-464, 2003.

31. Fagotto F, Funayama N, Gluck U and Gumbiner B: Binding to cadherins antagonizes the signaling activity of $\beta$-catenin during axis formation in Xenopus. J Cell Biol 132: 1105-1114, 1996. 
32. Tuschl T, Zamore PD, Lehmann R, Bartel DP and Sharp PA: Targeted mRNA degradation by double-stranded RNA in vitro. Genes Dev 13: 3191-3197, 1999.

33. Tijsterman M, Ketting RF and Plasterk RH: The genetics of RNA silencing. Annu Rev Genet 36: 489-519, 2002.

34. Fjose A, Ellingsen S, Wargelius A and Seo HC: RNA interference: mechanisms and applications. Biotechnol Annu Rev 7: 31-57, 2001.

35. Verma UN, Surabhi RM, Schmaltieg A, Becerra C and Gaynor RB: Small interfering RNAs directed against betacatenin inhibit the in vitro and in vivo growth of colon cancer cells. Clin Cancer Res 9: 1291-1300, 2003.
36. Pelengaris $\mathrm{S}$ and Khan M: The many face of c-myc. Arch Biochem Biophys 416: 129-136, 2003.

37. Nhieu JT, Renard CA, Wei Y, Cherqui D, Zafrani ES and Buendia MA: Nuclear accumulation of mutated beta-catenin in hepatocellular carcinoma is associated with increased cell proliferation. Am J Pathol 155: 703-710, 1999.

38. Montgomery MK: RNA interference: historical overview and significance. Methods Mol Biol 265: 3-21, 2004. 